\title{
HEAT TRANSFER AND PRESSURE DROP MEASUREMENT IN MINICHANNELS
}

\author{
Jiří HEJČíK, Miroslav JíCHA•
}

\begin{abstract}
This paper describes the suitable techniques for the heat transfer and pressure drop measurement in smooth tubular channels with the internal diameter less than $5 \mathrm{~mm}$. The first experimental data are mentioned and their evaluation is presented.
\end{abstract}

\section{INTRODUCTION}

The effort to achieve greater values of heat transfer coefficient has accompanied design engineers of heating equipment for almost 100 years [1]. Probably the easiest way of increasing it is to decrease the channel diameter (at least according to the classical correlations). Although this method seems to be very simple, its application is technologically very challenging, thus this method has only been used in special applications (e.g. military and aircraft industry) even though for a long time. The wider use of it occurs only in the last 20 years because of the growing interest in highly efficient and compact heat exchangers; mainly because of the need to cool a shrinking and more powerful electronics. The problem of heat transfer in channels of such a small diameter has grown in importance and some different categories were established during the last decade. Probably the most applied classification was defined in 2002 by Kandlikar [2] who divided the channels into 3 categories. The first category is called a conventional channel and contains channels with hydraulic diameters greater than $3 \mathrm{~mm}$. Next category called minichannels contains those with hydraulic diameters diameter in the range $200 \mu \mathrm{m}-3 \mathrm{~mm}$, and finally the last category is called microchannels where the channels range from $10 \mu \mathrm{m}$ to $200 \mu \mathrm{m}$.

The minichannel category is very interesting mainly for mechanical engineers because it allows designing small and effective heat exchangers which are not hypersensitive to the purity of the flowing media. However these heat exchangers seem to be convenient for lots of applications, the fact that there are no currently available reliable procedures for their design prevents their utilisation. The problem with a minichannel exchanger design is attributed to the heat transfer rate prediction. Although Kandlikar, et al. [3] stated that the correlations for conventional channels could be used, the research done on minichannels is not so clear.

\footnotetext{
- Ing. Jiří Hejčík, Ph.D.; Energy Institute, Faculty of Mechanical engineering, Brno University of Technology, Technická 2896/2, 61669 Brno; email: hejcik@fme.vutbr.cz prof. Ing. Miroslav Jícha, CSc.; Energy Institute, Faculty of Mechanical engineering, Brno University of Technology, Technická 2896/2, 61669 Brno; email: jicha@fme.vutbr.cz
}

This is an Open Access article distributed under the terms of the Creative Commons Attribution License 2.0, which permits unrestricted use, distribution, and reproduction in any medium, provided the original work is properly cited. 


\section{TEST RIG}

A minichannel test rig was built to prove the possibility of the conventional channel correlations application to tubular channels with inner diameter in range of $0.25-5 \mathrm{~mm}$. Compressed air was used as a test medium. It is stored in an air-pressure tank and it flows through the pressure reducing valve and the heater to the pressure/temperature header, where a temperature sensor is mounted as well as a pressure port for pressure drop measurement. Aftet that the air goes through a test section, where a tested minichannel is mounted and cooled by water or an ice-water mixture. The next temperature/pressure header is located after the test section to facilitate the temperature and pressure measurement. The compressed air mass flow measurement and regulation is located behind this head and it terminating the compressed air flow path. The schematic view of the rig is shown in the figure 1.



\section{Legend:}

1. air - pressure tank

2. pressure - reducing valve

3. heater

4. pressure/temperature header

5. test section

6. flowmeter

7. needle valve

Figure 1: Test rig

Thin wall stainless steel tubes were used as test channels in this test rig. They were inserted into the test section and joined to the pressure/temperature headers. Hence three additional temperature sensors were sticked on the minichannel surface to measure the wall temperature near the headers and in the middle of the minichannel. The test section was then filled up with water or ice-water mixture, so that the minichannel was fully submerged and the test rig was prepared for the heat transfer coefficient or pressure drop measurement.

\section{HEAT TRANSFER COEFFICIENT MEASUREMENT}

The required air pressure level and mass flow rate was preset by the pressure-reducing valve and the needle valve. Next, the heater was turned on and the system heated up for a couple of minutes. After that the pressure level and mass flow rate was tuned up to the required value and the measurement started. Temperatures, pressure drop and mass flow rate were the stored data collected every second for approximatelly 10 minutes. Then the new mass flow rate was set and the procedure repeated.

The heat transfer coefficient, $h$, is then calculated from the stored data using the equation for constant wall temperature heat transfer (1), which could be used due to the negligible thermal resistance of channel walls.

$$
h=-\frac{\dot{m} \cdot c_{p}}{\pi \cdot D \cdot L} \cdot \ln \left(\frac{T_{w}-T_{b, O U T}}{T_{w}-T_{b, I N}}\right)\left[\mathrm{Wm}^{-2} \mathrm{~K}^{-1}\right]
$$

where $\dot{m}[\mathrm{~kg} / \mathrm{s}]$ - air mass flow rate, $c_{p}[\mathrm{~J} / \mathrm{kg} / \mathrm{K}]$ - constant pressure specific heat of air, $D[m]$ - channel diameter, $L[m]$ - channel length, $T_{w}[K]$ - wall temperature, $T_{b, I N}$, $\mathrm{T}_{\mathrm{b}, \mathrm{OUT}}[\mathrm{K}]$ - compressed air inlet/outlet temperature to/from test section 
As can be seen in equation 1 , the heat transfer coefficient depends on the temperature difference between air and the wall. It means that the exact temperature measurement is crucial for the used method, which could be a problem in the case of small temperature differences, therefore the inlet temperature of compressed air has to be as high as possible to decrease the uncertainty of the heat transfer coefficient measurement.

\section{Pressure drop meAsurement}

There was no heater used for the pressure drop measurement. Only the required air mass flow rate (Reynolds number) was set and the pressure drop read. The problem was that pressure drop measured was not the one of the minichannel but the one of the compressed air flowpath from one pressure/tempereture header to the next one. It means it also includes some local pressure drops. Due to this another pressure drop measurement with a shortened minichannel had to be done to eliminate the local pressure drop effect. The minichannel friction factor was then calculated from the difference of the measured pressure drops (long and short minichannel) and the length of the cutted part of the minichannel.

\section{RESULTS}

First heat transfer coefficient measurement with $4.8 \mathrm{~mm}$ internal diameter smooth tubular channel was performed. The channel wall thickness was $0.2 \mathrm{~mm}$ and the channel length was $538 \mathrm{~mm}$. This "conventional" size channel was made of AISI 304 stainless steel and installed to the test rig to prove heat transfer coefficient measurements. The compressed air gauge pressure was set to 2 bar at the inlet side of the channel. The air was heated up to approx. $80^{\circ} \mathrm{C}$ and the test section was filled up with an ice-water mixture. The air flow rate varied in between 5 and $55 \mathrm{Nl} / \mathrm{min}$ to reach the Reynolds number values from 1500 to 15000 .

Although the constant wall temperature condition was supposed during the preliminary stage of experiments, the first measurement showed that we were not able to meet that condition. The alternative method (equation 2) based on the logarithmic mean temperature difference was used to calculate the heat transfer coefficient instead of equation (1).

$$
h=\frac{\dot{m} \cdot c_{p}}{\pi \cdot D \cdot L} \cdot \ln \left(\frac{T_{b, O U T}-T_{W, O U T}}{T_{b, I N}-T_{w, I N}}\right) \cdot \frac{T_{b, I N}-T_{b, \text { OUT }}}{\left(T_{b, \text { OUT }}-T_{W, O U T}\right)-\left(T_{b, I N}-T_{w, I N}\right)} \quad\left[\mathrm{Wm}^{-2} \mathrm{~K}^{-1}\right]
$$

Results obtained using equation (2) were transformed to the non-dimensional Nusselt number and compared with Gnielinski's correlation which is commonly used for in tube heat transfer coefficient calculation, see figure 2 . The pressure drop measurement has not been finished yet. 




Figure 2: Measured data

\section{DISCUSION}

Measured data are in a good agreement with the Gnielinski's correlation for the Reynolds Number between 7000 and 15000 (figure 2), where the relative difference between measured and calculated data is lower than $8 \%$. There is a big difference in measured and calculated values for the Reynolds numbers lower than 4000 though, where the relative difference almost reaches $40 \%$. It is probably caused by flow transition from laminar to turbulent flow, but there is no physical evidence for it.

The selected method and measurement techniques seems to be suitable for the heat transfer coefficient measurement, as could be seen from the measured and calculated data comparison in figure 2. But there are still some things to improve, mainly in the field of data processing, where some different techniques e.g. Wilson plot method should be used for the heat transfer coefficient calculation.

\section{ACKNOWLEDGEMENT}

The authors would like to greatly acknowledge the financial support received from the Czech Science Foundation (under the project No. P101/11/P538) and from the Faculty of Mechanical Engineering, Brno University of Technology (project No. FSI-S-11-6).

\section{REFERENCES}

[1] Steinke, Mark E.; Kandlikar, Satish G.: Single-phase heat transfer enhancement techniques in microchannel and minichannel flows. In. Proceedings of the second international conference on microchannels and minichannels, June 17-19, 2004. Rochester, USA : ASME, 2004. pp. 141-148. ICMM2004-2328.

[2] Kandlikar, Satish G.: Fundamental issues related to flow boiling in minichannels and microchannels. Experimental Thermal and Fluid Science. 2002, Vol. 26, Issue 2-4, pp. 389-407. ISSN 08941777.

[3] Kandlikar, Satish G., et al.: Heat transfer and fluid flow in minichannels and microchannels. 1st ed. Amsterdam, Netherlands : Elsevier, 2006. 450 p. ISBN 9780-08-044527-4. 